\title{
Research on the Infiltration and Integration of Modern Dance Elements in Folk Dance Teaching
}

\author{
Shu Zhang \\ Department of Dance, School of Music, Shanxi University, Shanxi 030006, Taiyuan, China \\ Email: 343481934@qq.com
}

\begin{abstract}
The Chinese nation is a great integration of 56 ethnic groups. The long national history has created the culture of different ethnic regions, and the dances of each ethnic group have their own characteristics. As one of the important historical and cultural heritages of our country, folk dance plays an important role in the spiritual development of the people and the improvement of happiness index. However, with the continuous progress of the times and society, the spiritual level people pursuit is getting higher and higher. If we want folk dance to adapt to the development of the times and society, and continue to carry forward, we must make corresponding innovations. The most obvious way of innovation is to infiltrate and integrate with modern dance. This article will study the respective advantages of folk dance and modern dance, as well as how to carry out infiltration and innovation of integration and development, so as to promote the development of folk dance and help it build a broader mass base.
\end{abstract}

Keywords: modern dance, folk dance, infiltration and integration, dance teaching

\section{Introduction}

With the progress and development of society and the times, the closeness of Sino-foreign exchanges has increased, and people's life concepts, aesthetic tastes, and emotional expressions have undergone corresponding changes. Due to the impact of modern concepts on traditional concepts, folk dance is also in urgent need of development. As a traditional dance form, folk dance must adopt a brand-new attitude to ensure the audience if it wants to develop better. This requires innovation and changes in dance form, dance structure, and dance emotions. How to make its development not only retain national characteristics, but also keep pace with the times, has become a question worth pondering for all dancers who love folk dance. As modern dance, as a new dance form, has a broad audience, infiltrating and integrating modern dance styles and elements into folk dance has become a shortcut for the innovation and development of Chinese folk dance.

\section{Analysis of the existing problems of folk dance}

\subsection{Deep-rooted traditional concepts}

Folk dance is a form of dance performance that integrates ethnic customs, ethnic customs, ethnic culture and other elements. The teachers and choreographers of folk dance are mostly scholars who study dance inheritance with great concentration. The inherent traditional concepts prevent them from accepting many new forms and concepts from the heart during the teaching and choreographing process, which has led to the limitation of innovation and poor inheritance prospects of folk dance. To better inherit and develop folk dance, teachers and choreographers must first change their concepts, get in touch with and like some new dance forms and materials, and infiltrate and integrate them appropriately so that more people can love folk dance.

\subsection{Difficulties in model innovation}

China has a vast territory and has 56 ethnic groups with different folk customs. The ancient folk dance styles are very different, each with its own characteristics. In order to pass on the customs and cultural habits of various nationalities, the inheritors are generally unwilling to break their original traditional patterns, and they lack acceptance of other dance elements, which ultimately leads to the lack of innovation in folk dance. However, traditional folk dance can no longer match people's increasingly broad vision and more complex aesthetic standards. If folk dance wants to overcome all difficulties and be loved by the public and achieve greater development, it must actively seek innovation. 


\subsection{Some choreographers are eager for quick success and quick profit, blindly choosing inappropriate dance elements}

With the development of society, some choreographers realized the bottleneck in the current stage of folk dance, so they took the initiative to innovate folk dance. However, due to limited conditions, some choreographers could not thoroughly study the beneficial connections between dances. They were only inspired by external dance elements, superimposing the two together, and blindly absorbing the essence and dross of the dance. This not only destroys the coordination of folk dance, but also destroys the connotation and folk custom characteristics that folk dance should have, making it nondescript, and ultimately affecting its development.

\subsection{Various folk dance performances can easily mislead the audience}

With the improvement of the economic level and the enrichment of people's lives, the tourism industry has developed accordingly. Many performance groups are optimistic about the market for folk dance in the tourism industry and use it to develop tourism. However, the excessive consumption of folk dance and the consideration of market demand have caused the distortions of folk dance in the form of performance, situation, and body charm. ${ }^{[1]}$

\section{The characteristics of folk dance and modern dance}

\subsection{The characteristics of folk dance}

Folk dance is a kind of dance derived from people's lives, and its dance elements are just an artistic display of the life style passed down by the people of various nationalities for thousands of years. Due to the differences in regions and living habits, the customs, religious beliefs and physical shapes of people of different ethnic groups are also different, so the folk dances derived from them are also different. Traditional folk dances are mostly ceremonial dances, which have specific symbolic significance, and are narrative and inheritance. With the changes in history, ethnic events will leave traces in the form of dance, and will continue to be integrated and passed on.

\subsection{The characteristics of modern dance}

Modern dance is a new form of dance that is popular around the world. It is based on the rapid development of economic, cultural and social society, and has a distinctive era. Its development is similar to that of folk dance, but it can incorporate the essence of dance from various countries. In addition, modern high-tech and cool expression methods and techniques have added a lot of vitality to the expression and content of modern dance. Timeliness and advancement are its main characteristics. And its expression content focuses more on story plots, thoughts and emotions, and reflects social needs and human emotions through dance body movements, with strong openness and expressiveness. ${ }^{[2-3]}$

\section{Modern dance elements and the penetration and development of folk dance}

\subsection{Refine modern dance techniques and apply them to folk dance}

The dancer's dance passion is shown to the audience by showing dance skills, and the mastery of skills requires constant polishing and exercise by the dancers. In the process of gradually mastering the skills, dancers can innovate and sublimate their skills and discover new skills. Modern dance is a type of dance that keeps pace with the times and is constantly improved with the progress of the times and society. It will not be constrained by inherent patterns, but will continue to improve and derive during the training process. In terms of thinking and skills, there are places that folk dance can learn from. Seeking common ground while reserving differences and being brave to innovate is the key to incorporating modern dance techniques into folk dance. Only by retaining the exquisite and delicate characteristics of folk dance, adding the warm emotions of modern dance, and expressing them with skilled techniques and graceful dance gestures, can the overall effect of the dance be more effectively improved. The integration of modern dance techniques into folk dance can better provide a basis for expressing the national and regional characteristics of folk dance. It also makes the artistic forms of folk dance more diversified and more creative in dance expression.

\subsection{Reasonable infiltration and integration of modern dance and folk dance}

The key to the inheritance of folk dance is to teach. However, with the progress of the times and the gradual development of social economy, it is necessary to adjust the teaching methods and concepts in the teaching process, so as to ensure that the folk dance is better inherited. Only in this way can it attract more scholars and dance enthusiasts to enter the field of folk dance, and enable them to grasp the essence of folk dance more quickly and quickly express its essence. The prerequisite for infiltrating modern dance into folk dance is to completely retain the national and regional characteristics 
of folk dance, and to express the dancer's inner feelings more clearly. This requires teachers and choreographers to fully understand modern dance and folk dance, then open up more era characteristics for folk dance, and organically penetrate and blend the two. It is also necessary to guide dancers and audiences to understand the connotation of folk dance through the expressions of modern dance and folk dance, and ultimately enable modern dance and folk dance to be better inherited and developed. ${ }^{[4-6]}$

\subsection{The emotional expression of folk dance should be contemporary}

Folk dance is a type of dance that originates from people's life and labor, and it should have the characteristics of the times. With the change of times, the emotions expressed by dance should also be changed. The artistic beauty of dancers comes from the expression of people's life, labor and spiritual needs, so teachers and dance choreographers need to have keen insight to understand the aesthetic level and spiritual thinking of the people in the process of the change of times, along this road creating folk dance works with the influence of the times. Because modern dance is a model of contemporary people's aesthetic standards and emotions into the dance, the aesthetic form of dance art can be selected and incorporated into the folk dance, which can add more sense of the times to the folk dance. The fusion and absorption of modern dance and folk dance can better create a foundation for the development of folk dance itself, and give it a better time foundation for inheritance and development. ${ }^{[7]}$

\subsection{Let modern dance elements help folk dance}

Folk dance is too traditional, which makes it suffer certain resistance in the process of inheritance and development. In order to get a better inheritance and development, the inheritors need to consciously add modern music ${ }^{[9]}$ and dance elements to the national folk dance, so that they can keep up with the pace of the times and comply with the development of the times and social life, so that they will not be abandoned by the times. Only by having a mass foundation can we better retain the regional and ethnic characteristics of folk dance. Therefore, in the process of dance creation, teachers and choreographers can consider applying modern music, dance, lighting and other elements to folk dance, so that folk dance can retain the traditional characteristics and have more fashion sense at the same time. Only in this way can folk dance get more vitality and more people, and even the whole world, see and love Chinese folk dance. ${ }^{[8]}$

\section{Conclusion}

Folk dance must conform to the development of the times and society, keep up with the trend of the times, and continue to innovate in order to get better inheritance and progress. The integration of modern dance can add more fashionable colors to folk dance, thereby presenting the essence of the nation to the world, and finally giving the Chinese folk dance the opportunity to go abroad and into the world. ${ }^{[10]}$

\section{References}

[1] Jin Nina. Thought on the Secondary Folk Dance Teaching Reform. Modern Vocational Education. $2017 ;$ (03): 136.

[2] Xiao Xiao. Features and expressions of folk dance and modern dance. Participate in the Flower (Part 2). 2018; (01): 155.

[3] Ye Wenyang. Analysis of the aesthetic difference between national dance and modern dance. The House of Drama. 2018; (36): 110.

[4] Liu Shuai. Research on the practice of fusion of modern dance elements in folk dance teaching. Popular Literature and Art. 2018; (11): 200-201.

[5] Wang Peng. Exploration of the integration of modern dance elements in folk dance teaching. Xueyuan. 2017 ; (20): 58.

[6] Gao Chuang. Analysis of the integration of modern dance elements in the teaching of ethnic dance. Art Research. 2018; (03): 128-129.

[7] Fan Yanhua. Exploration of the fusion of modern dance elements in the teaching of ethnic dance. Music Magazine. 2013; (19): 201.

[8] Liu Qingyi. "Going Local" and "Integrating with the World" — On the conflict and integration of Eastern and Western dance culture. Dance. 2000; (02): 44-46.

[9] Li Xin. A brief discussion on the relationship between music and dance. Journal of Educational Institute of Jilin Province (Discipline Edition). 2009; (04): 20-21.

[10] Luo Juan. Talking about the characteristics and development trend of ethnic dance. Voice of the Yellow River. 2018; (16): 131. 